\title{
Projections of global mean sea level rise calculated with a 2D energy-balance climate model and dynamic ice sheet models
}

\author{
By J. R. DE WOLDE ${ }^{1}$ *, P. HUYBRECHTS ${ }^{2}$, J. OERLEMANS ${ }^{1}$ and R. S. W. VAN DE WAL ${ }^{1}$ \\ ${ }^{1}$ Institute for Marine and Atmospheric Research, Utrecht Unicersity, P. O. Box 80005,3508 TA Utrecht, \\ The Netherlands, ${ }^{2}$ Geografisch Instituut, Vrije Universiteit Brussel, Pleinlaan 2, B-1050 Brussels, Belgium
}

(Manuscript received 22 July 1996: in final form 14 May 1997)

\begin{abstract}
Projections of changes in surface air temperature and global mean sea level over the next century are presented for all IS92 radiative forcing scenarios. A zonal mean energy-balance climate model is used to estimate temperature changes and thermal expansion, precipitationdependent sensitivity values are used to estimate the sea-level contribution of glaciers and small ice caps and dynamic ice-sheet models coupled to surface mass balance models are employed with regard to the Greenland and Antarctic ice sheets. A few of the sea-level projections have been included in the IPCC96-report for comparison with the revised IPCC96 projections. Here it is demonstrated that the observed inter-model differences are similar for all IS92 radiative forcing scenarios: the projections of global surface air temperature change resemble the revised IPCC96 projections, but the projections of global sea-level rise are $30 \%-50 \%$ smaller than the revised IPCC96 projections. In this paper, the reasons for the inter-model differences in sealevel results are considered. The largest inter-model differences in individual sea-level contributions are found for thermal expansion and for the Antarctic ice-sheet. Sensitivity experiments are presented that show the importance of different assumptions about the temperature forcing of the glacier and ice-sheet models and about weakening of the ocean circulation. Furthermore, uncertainties in thermal expansion caused by uncertainties in ocean heat mixing are considered. It is concluded that the inter-model differences in sea-level projections are caused by the use of essentially different models in this paper and in the revised IPCC 96 projections.
\end{abstract}

\section{Introduction}

Changes in sea-level related to potential future global warming are of great interest for human beings. Projections of sea-level change, however, are subject to large uncertainties. On time scales of decades to a century, global sea-level is affected mainly by thermal expansion of sea water and by changes in the volume of the Greenland ice-sheet, the Antarctic ice-sheet and glaciers and small ice caps. Therefore, projections of sea-level change

\footnotetext{
* Corresponding author. e-mail: J.deWolde(afys.ruu.nl
}

are often based on these 4 components only (Warrick and Oerlemans, 1990; Warrick et al.. 1996). However. the observed sea-level rise over the last 100 years cannot be easily explained by means of these 4 components only. Best estimates indicate that the global mean sea-level has risen by $18 \mathrm{~cm}$ during the last 100 years. whereas the combined estimates of the 4 individual contributions add up to only $8 \mathrm{~cm}$ (Warrick et al., 1996). In order to account for the "unexplained" part of the observed sea-level rise, one could consider including an extrapolated historical trend in the projections of future sea-level change. Since the observed range of recent sea-level rise falls within 
the extremities of the combined estimates of the individual contributions, such an approach was not followed in the IPCC96-report (Warrick et al., 1996).

In the IPCC96-report, 2 sets of sea-level projections are presented, both of which are based on estimates of the combined sea-level contributions of thermal expansion, glaciers and small ice caps and the Greenland and Antarctic ice sheets. For the first set of sea-level projections, a onedimensional (1D) upwelling-diffusion model was used to project changes in sea-level caused by thermal expansion (Wigley and Raper, 1992; Raper et al., 1996). The contribution of glaciers and small ice caps was assessed by use of a global glacier melt model (Wigley and Raper, 1995) and the contributions of the Greenland and the Antarctic ice sheet were calculated by the use of static sensitivity values that ignore any dynamic response. These sea-level projections were called the revised IPCC projections, because apart from some revisions, the models used are similar to those used in the IPCC90-report (Warrick and Oerlemans, 1990). Since several alternative models have been developed recently, a 2 nd set of sealevel projections has been included in the IPCC96-report in order to demonstrate intermodel differences. This set of sea-level projections is based on essentially different models: a 2-dimensional (2D) seasonal climate model was used to estimate thermal expansion, precipitationdependent sensitivity values were used to estimate the sea-level contribution of glaciers and small ice caps and two dynamic ice-flow models coupled to surface-mass balance models were used to estimate the contributions of the Greenland and Antarctic ice sheets.

Although the inter-model comparison is a valuable section of the IPCC96-report, it would have been better to include results from coupled atmosphere-ocean general circulation models as well. Unfortunately, so far those coupled models have been used in only a few climate change studies and too much computer time is required to perform many scenario-runs. Therefore, comparable estimates of future sea-level change are based on only the first 2 approaches.

The projections of sea-level rise calculated by means of the 2D climate model and the dynamic ice-sheet models turned out to be considerably smaller than the revised IPCC-projections. In this paper, the differences between the 2 sets of projections are considered. We will present the sea-level projections that are based on the 2D climate model and on the dynamic ice-sheet models for all adjusted IS92 radiative-forcing scenarios (Kattenberg et al., 1996). Since the methods followed for these projections differ from those used for the revised IPCC-projections, we will elucidate our methods in more detail and we will consider the consequences for sea-level change if alternative methods are followed. Uncertainties in the individual contributions to sea-level change which are caused by uncertainties in model parameters will also be discussed.

\section{Models and methods}

In this section, a brief description of the zonal mean climate model and the ice models will be given. Thereafter, we will explain how the ice models are driven by the temperature output produced by the zonal mean climate model.

\subsection{The zonal mean climate model for thermal expansion}

In the present study, a $2 \mathrm{D}$ energy-balance climate model is used to estimate thermal expansion of sea water. The model has a vertical and latitudinal resolution and resolves the seasonal cycle. The ocean model consists of 3 zonally-averaged ocean basins, representing the Atlantic, Pacific and Indian Oceans, which are connected by a circumpolar ocean basin, representing the Southern Ocean. The model has a prescribed ocean circulation and includes several parameterizations of ocean heat mixing due to unresolved eddies. The ocean temperature field is affected by ocean heat mixing, by advection by the mean flow and by heat exchange at the surface. The ocean model is identical to that described by De Wolde et al. (1995), but now has an uppermost layer thickness measuring $75 \mathrm{~m}$. Furthermore, a representation of sea ice is included in the model. Since horizontal variations in sea-ice extent are assumed to affect the surface energy budget most by means of the albedo, these are calculated as described by Bintanja (1997). Sea ice forms with a specified thickness of $1.5 \mathrm{~m}$ and the formation is determined by thermodynamics only. The ocean 
model is coupled to an energy-balance model of the atmosphere (Bintanja, 1997). In this model, the atmosphere is represented by a vertically- and zonally-averaged layer of air. The surface air temperature results from radiative fluxes at the surface and at the top of the atmosphere, from turbulent fluxes between the atmosphere and the surface and from heat transport. Meridional heat transport is modelled as a diffusive process in terms of the atmospheric surface air temperature, whereas the "infinite wind" case is adopted to calculate zonal heat transport, which means that one effective atmospheric layer is assumed that overlies the land as well as the ocean part of a latitudinal band. The continents are represented by a single strip of land. The temperature of the land surface is determined by the net long-wave and shortwave radiation and by turbulent heat fluxes at the surface. The climate sensitivity of the zonal mean climate model (defined as the equilibrium global mean surface air temperature increase due to a doubling of the $\mathrm{CO}_{2}$ concentration) is $2.2^{\circ} \mathrm{C}$, close to the best estimate of $2.5^{\circ} \mathrm{C}$ based on observational evidence, on general circulation model studies and on sensitivity analyses (Mitchell et al., 1990).

The climate model was calibrated against the seasonal cycle of present-day observations of surface air temperature, ocean temperatures and snow and sea ice cover. However, because the observed historical warming is expected to affect future thermal expansion, model calculations have to start from a pre-industrial initial state for which unfortunately no observational data exist. Therefore the model climate was first cooled from present-day conditions to a 1765 initial state by means of the adjusted IS92 radiative-forcing value corresponding to 1990 but referenced to 1765 . Starting all the time from that initial model state, the climate model was integrated over the period $1765-2100$ for all IS92 radiative-forcing scenarios, following the observed radiative forcing up to 1990 and the radiative-forcing scenarios thereafter. Model outputs include sea-level rise due to thermal expansion and changes in the surface air temperature field. The latter are used as input for the glacier and ice-sheet models, yielding the land ice contribution to sea-level change.

\subsection{Glaciers and small ice caps}

Because individual glaciers and small ice caps have a different response to global warming, we would prefer to apply a dynamic ice-flow model coupled to a surface mass balance model for each glacier. Unfortunately, this cannot be done for most glaciers since insufficient observational data exist to construct and validate such models. However, mass-balance-model studies of wellobserved glaciers show that glaciers in a wetter climate are more sensitive to changes in air temperature than glaciers in dry regions (Oerlemans and Fortuin, 1992). This arises because the hypsometry (area-elevation distribution) is essentially different and the albedo feedback is more effective for glaciers with high-precipitation snowfall. To take these effects into account, we follow the method introduced by Oerlemans and Fortuin (1992) to estimate the sea-level contribution of glaciers and small ice caps: all glaciers and small ice caps on Earth have been divided into 100 regions, each characterised by the present-day precipitation rate and glacierized area. For each region, we use precipitation-dependent sensitivity values (derived from model studies on wellobserved glaciers) to calculate changes in the specific mass balance which result from an increase in atmospheric temperature. From these massbalance changes, we calculate changes in glacier volume by assuming that the glacierized area remains constant.

Since precipitation is not determined in the zonally averaged climate model and because changes in precipitation patterns in climate scenario runs produced by coupled atmosphere-ocean general circulation models are still uncertain, the precipitation-rate for each region is kept constant. Therefore, the applied glacier-sensitivity values do not vary in time if a constant glacierized area is assumed. For the larger glaciers and ice caps, which contribute most to the total change in ice mass, this is a reasonable assumption (on the time scales considered here). On the other hand, this assumption is a poor approximation for the smaller glaciers, but it is not clear how changes in the glacier volume should be related to changes in area. However, this approximation hardly affects the total sea-level contribution, since small glaciers only have minor contributions to the total change in ice mass.

Model calculations start in 1990, because the sensitivity-values are determined for present-day conditions and because the present-day precipitation rate is used. However, at the present time, 
most glaciers are not in equilibrium. To account for the observed present-day thinning of several glaciers, projections of the contribution of glaciers and small ice caps to sea-level change include a constant long-term trend of $0.5 \mathrm{~mm} \mathrm{yr}^{-1}$ sea-level rise. This value is the model calculated sea-level contribution at present, if forced with the observed historical temperature increase, and is consistent with estimates based on observations of glacier retreat (Meier, 1984; Schwitter and Raymond, 1993).

\subsection{The Greenland ice sheet}

General circulation models (GCMs) are used to simulate the Greenland and Antarctic surface climate variables, but their ability to study massbalance changes in response to global warming is still limited. Coarse-grid GCMs do not have a fair representation of the surface topography, whereas high-resolution GCMs demand too much computer time to perform climate scenario runs. Recently. Ohmura et al. (1996) presented changes in the surface-mass balances of the Greenland and Antarctic ice sheets in 2 snapshot experiments $\left(1 \times \mathrm{CO}_{2}\right.$ and $\left.2 \times \mathrm{CO}_{2}\right)$ carried out with a highresolution GCM. But since their results are too preliminary to be used in climate scenario runs, we applied separate ice-sheet models to estimate the Greenland and Antarctic sea-level contributions.

The Greenland ice-sheet model is a $2 \mathrm{D}$ model that has a horizontal resolution of $20 \times 20 \mathrm{~km}$. The ice-flow dynamics are based on fundamental physical equations, but are described in a single vertically-averaged layer (Van de Wal and Oerlemans, 1997). Ice velocity is determined by the local driving stress. The time-dependent model includes sliding in a parameterized form and an isostatic response of the underlying bedrock to a changing ice load. The ice thickness and the surface mass balance are entirely coupled. The model is forced with different temperature scenarios which change the surface mass balance. The ablation is calculated with an energy-balance model (Van de Wal and Oerlemans, 1994). Because changes in precipitation in Greenland appear to be determined importantly by the atmospheric circulation, it is uncertain how this will change in a changing climate. Ohmura et al. (1996) found an increase in precipitation for most regions, except for the coastal zone in the south-east and the north-western slope, where precipitation decreased. The change in total accumulation was very close to zero. We decided to keep the accumulation rate constant at its present-day value as described by Ohmura and Reeh (1991). Model calculations start in 1990 and the initial state of the coupled energy balance ice flow model is the dynamic equilibrium state for present-day conditions. Several sensitivity experiments carried out with the coupled energy balance ice flow model are described in Van de Wal and Oerlemans (1997).

\subsection{The Antarctic ice sheet}

The Antarctic ice-sheet model (Huybrechts, 1990; Huybrechts and Oerlemans, 1990) is a 3D thermomechanical model of the ice sheet, which takes into account a coupled ice shelf. groundingline dynamics, basal sliding and isostatic bed adjustment and which considers the fully-coupled velocity and temperature fields. It is coupled to a mass balance model that is driven by temperature perturbations interpolated onto a $40-\mathrm{km}$ grid. The accumulation rate on the Antarctic ice-sheet, which primarily determines the Antarctic mass balance, appears to be strongly related to the air temperature (Ohmura et al., 1996), which controls the amount of water vapour that can be advected inland. The accumulation rate in the model is therefore derived from present-day observed values and is subsequently perturbed in proportion to the saturation water vapour pressure. The ablation in Antarctica is of minor importance: it is calculated following the degree-day method which was the method used in modelling the Greenland ice-sheet (Huybrechts et al.. 1991). The initial state of the ice-sheet was obtained by integrating the ice-sheet model over 100,000 years, including the simulation of the 2 latest glacial cycles. The model response at the present time shows a positive present-day contribution to sealevel rise. For several reasons, this result has to be interpreted with the necessary caution and there is insufficient evidence from observations to conclude whether the present-day average mass balance is positive or negative. For this reason, the trend is not included in our projections of the sealevel contributions of the Antarctic ice-sheet. 

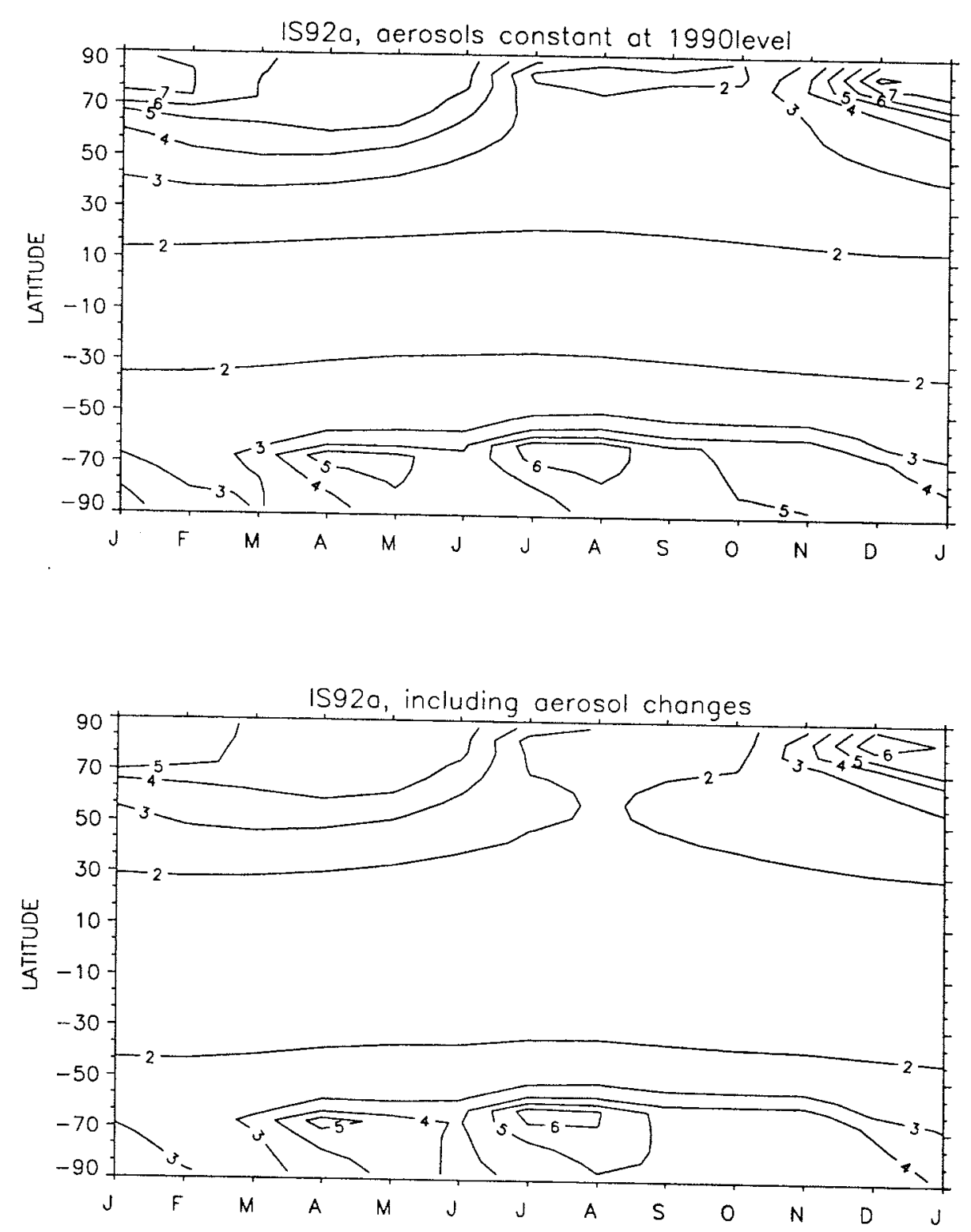

Fig. 1. Atmospheric temperature changes $\left({ }^{\circ} \mathrm{C}\right.$ ) in 2100 (referenced to 1990 ) calculated with the zonal mean climate model for the updated IS92a Scenario, with aerosols constant at 1990 level (upper plot) and with the inclusion of aerosol changes (lower plot).

\subsection{Methods}

The zonal mean climate model is integrated over the period $1765-2100$ for each of the 12 updated IS92 radiative forcing scenarios (both for constant 1990 aerosols and for increasing aerosol concentrations after 1990: Kattenberg et al., 1996). Besides calculating thermal expansion of sea water, the climate model also calculates latitudinally- and seasonally-varying changes in surface air temperature. Fig. 1 shows the temperature changes in the year 2100 , referenced to the year 1990 , calculated for the updated IS92a radiat- ive forcing scenario. The climate model calculates a temperature change that increases polewards, which results from the albedo-temperature feedback related to the sea ice and snow cover. The temperature changes in the Northern Hemisphere are somewhat larger than in the Southern Hemisphere, because of differences in the land-sea distribution and in the strength of the albedotemperature feedback. In both hemispheres, the polar temperature change varies considerably with the season. A larger temperature change is projected for winter than for summer, due to the thermal insulation effect of sea ice. In summer, the 
additional radiative energy is used mainly to melt sea ice and to warm the upper ocean, which prevents a large atmospheric warming. Due to the warming of the upper ocean, sea-ice formation is delayed in winter, thereby prolonging the atmospheric warming. This pattern of surface air temperature change is also seen in the other radiative forcing scenarios.

The seasonally- and latitudinally-varying changes in atmospheric temperature, calculated by the zonal mean climate model, are used to drive the dynamic ice-sheet models for Greenland and Antarctica and to calculate the sea-level contributions of glaciers and small ice caps. The temperature forcing for high-latitude glaciated regions is therefore larger than for mid-latitude glaciated regions, because of the poleward amplification of the atmospheric temperature increase. Since the glacier and ice-sheet models have been tuned to the present-day climate, the models are forced with temperature perturbations referenced to the year 1990 and the calculations start in 1990. An earlier start of the calculations would require initial model states that correspond to the conditions of glaciers and ice sheets in the past. Unfortunately, insufficient observational data are available to define such model states. Assuming some past initial model states, validation of the models against observed behaviour in the last century also suffers from a lack of observational information. Glaciers, for which reliable massbalance observations extending over a number of years exist, were considered to construct the glacier-melt model. However, with respect to the Greenland and Antarctic ice-sheets, it is unclear whether the average mass balances in the last century have been positive or negative (Warrick et al., 1996). The dynamic ice-sheet models coupled to the mass-balance models respond in a nonlinear way to a changing climatic input (the sensitivities of the coupled models increase with increasing temperature perturbations) (Van de Wal, 1996). The use of a pre-1990 reference date, but assuming a present-day initial model state would then cause an overestimation of the post-1990 contribution to sea-level change. Model calculations therefore start in 1990.

\section{Temperature and sea-level projections for the IS92a-f scenarios}

Projections of global mean temperature and sea-level changes have been made for all updated
IS92a-f radiative forcing scenarios. The projections of the increase in global and annual mean atmospheric temperature for the period 1990-2100 are shown in Fig. 2. The projected temperature changes are similar to those obtained with the 1D upwelling-diffusion model (Raper et al., 1996) used in the IPCC96-report, although the climate sensitivity of the $2 \mathrm{D}$ climate model $\left(2.2^{\circ} \mathrm{C}\right)$ is somewhat smaller than the prescribed central value in the $1 \mathrm{D}$ model $\left(2.5^{\circ} \mathrm{C}\right)$. The projected changes in global mean sea-level are shown in Fig. 3. Over the next few decades, the differences in sea-level rise for the various emission scenarios are small. By the year 2050, the values range between 11 and $15 \mathrm{~cm}$ (aerosols constant at 1990 level) and between 10 and $11 \mathrm{~cm}$ (including aerosol changes). After 2050, the uncertainties related to the emis-
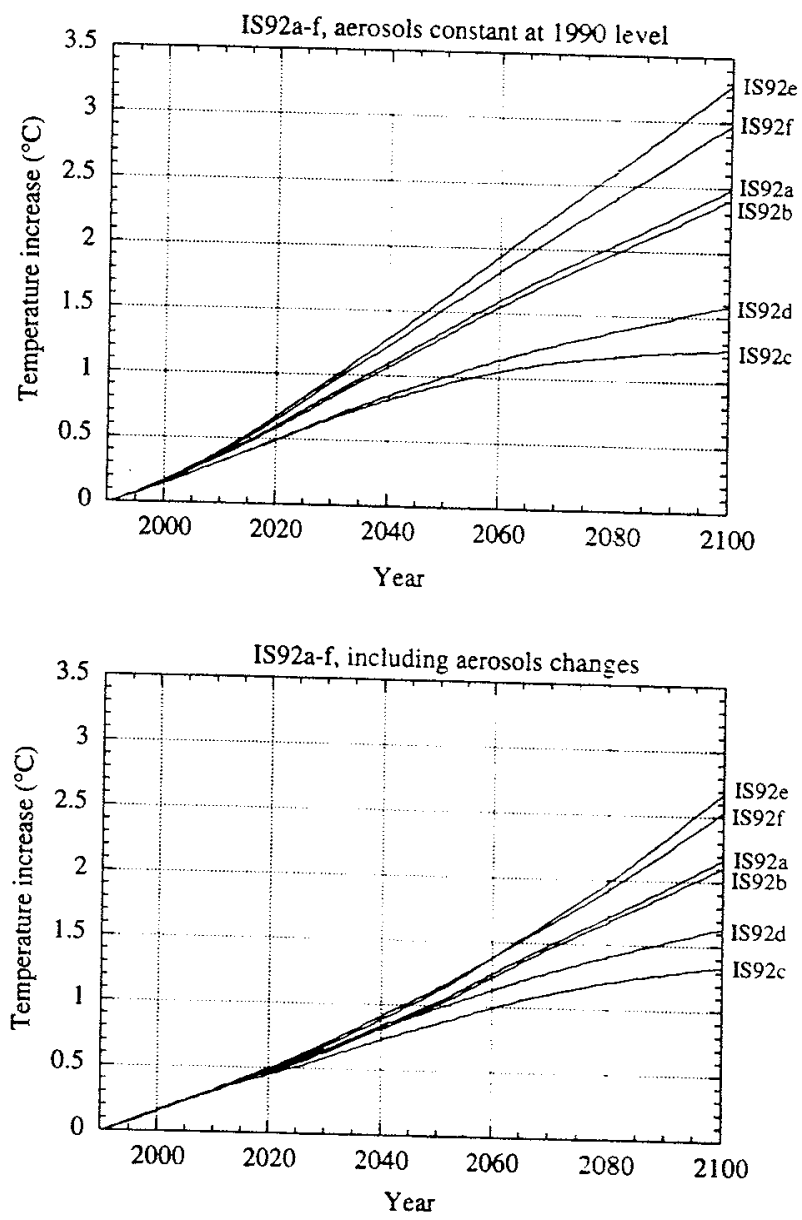

Fig. 2. Global and annual mean atmospheric temperature changes $\left({ }^{\circ} \mathrm{C}\right)$ from 1990 to 2100 , calculated with the zonal mean climate model for the updated IS92 radiative forcing scenarios, with aerosols constant at the 1990 level (upper plot) and with the inclusion of aerosol changes (lower plot). 

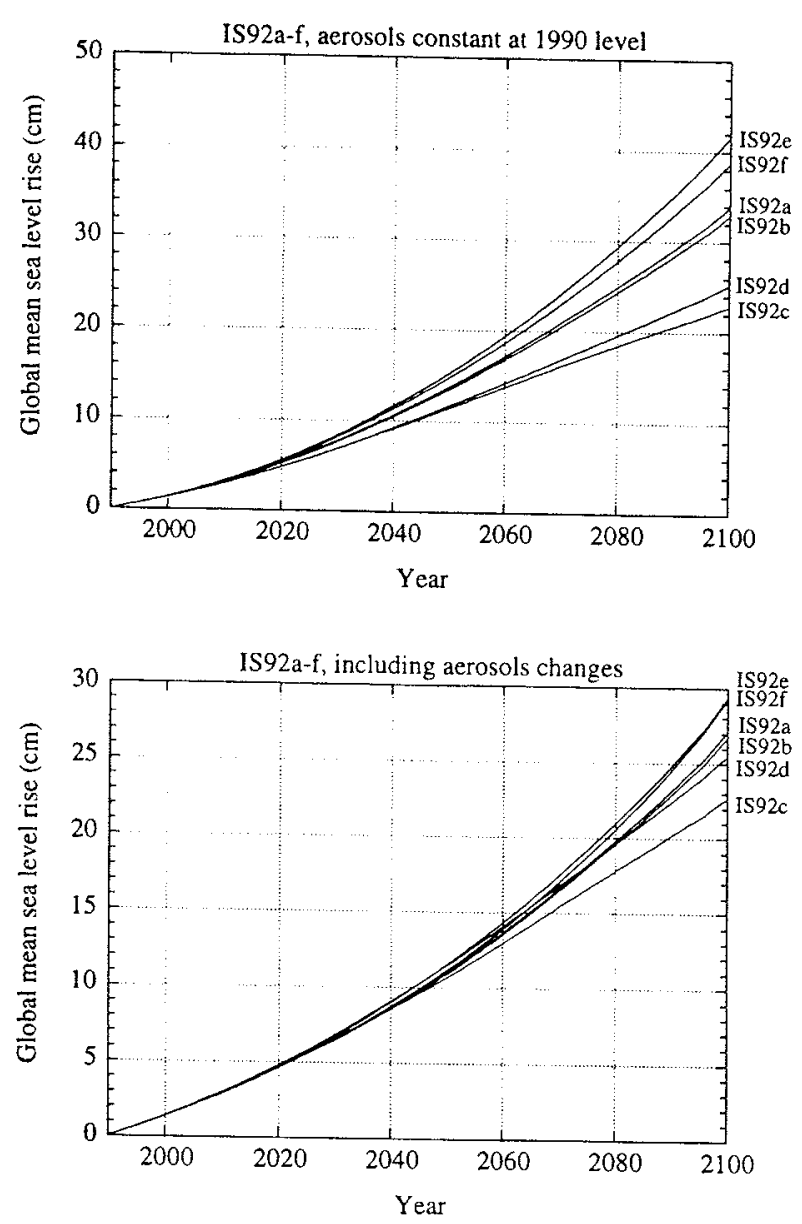

Fig. 3. Global mean sea-level changes $(\mathrm{cm})$ from 1990 to 2100 , for the updated IS92 radiative forcing scenarios, with aerosols constant at 1990 level (upper plot) and with the inclusion of aerosol changes (lower plot). Note that the vertical scale is different for the upper and lower plot.

sion scenarios increase. By the year 2100 , the projections of sea-level rise for various emission scenarios range from 23 to $42 \mathrm{~cm}$ (aerosols constant at 1990 level) and from 23 to $29 \mathrm{~cm}$ (including aerosol changes).

Fig. 4 shows the individual sea-level contributions of thermal expansion, of glaciers and small ice caps and of the Antarctic and Greenland ice sheets for the IS92a radiative-forcing scenario (both for aerosols constant at 1990 level and for the inclusion of aerosol changes). During the first few decades, the rate of thermal expansion is determined mainly by the pre-1990 changes in radiative forcing because of the thermal inertia of the oceans, and the sea-level contributions of glaciers and small ice caps are dominated largely
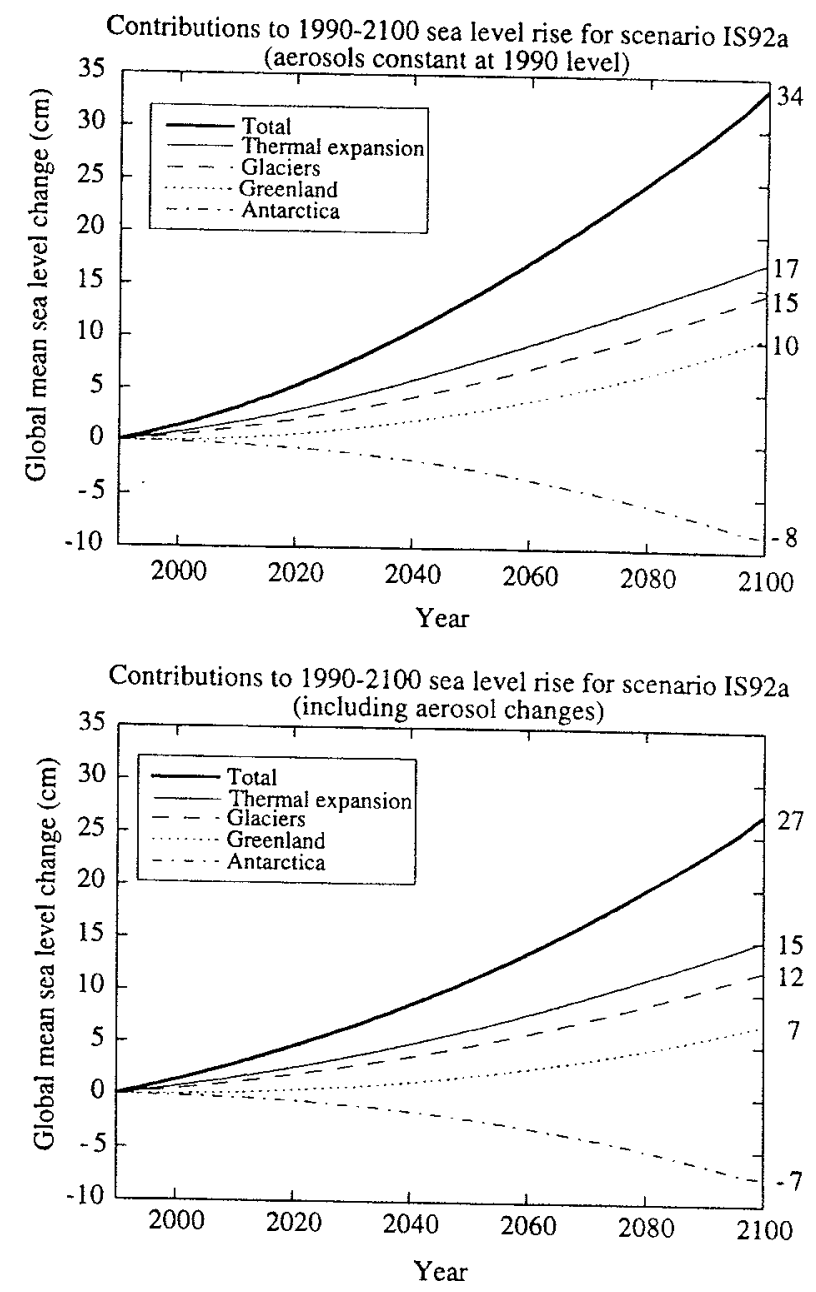

Fig. 4. Projected individual contributions and total sealevel change $(\mathrm{cm})$ from 1990 to 2100 , for the updated IS92a Scenario with aerosols constant at 1990 level (upper plot) and with the inclusion of aerosol changes (lower plot).

by the extrapolated present-day disequilibrium of most glaciers. Therefore, the projected sea-level contributions are found to be similar for all forcing scenarios. Later on, the projected sea-level contributions for the scenarios differ more from each other, but for all scenarios, the main part of the projected sea-level rise is caused by thermal expansion: by the year 2100 , the contribution of thermal expansion is about half of the total sea-level rise. The estimated contribution of glaciers and small ice caps is somewhat smaller. The Greenland icesheet contributes to a sea-level rise. due to enhanced ablation, but the Antarctica ice-sheet causes a sea-level drop because of an increased accumulation. 


\section{Comparison with the revised IPCC96 sea- level projections}

Our projections of sea-level rise differ considerably from the (central) revised IPCC-projections, although they lie within the large range of extreme IPCC-projections (Warrick et al., 1996). For all IS92 radiative forcing scenarios, we find that the revised IPCC-projections produced with the $1 \mathrm{D}$ upwelling-diffusion model, with the global glaciermelt model and with static sensitivity values for the ice sheets, are $1.5-2 \times$ as large as our projections. The individual sea-level contributions and total sea-level rise, for both sets of projections, over the period 1990-2100, which were calculated for the IS92a radiative forcing scenarios, are shown in Table 1. The largest inter-model differences in individual sea-level contributions are found for thermal expansion and for the Antarctic ice-sheet. The 2 sets of projections agree better in the estimated contributions of the Greenland ice-sheet and of glaciers and small ice caps, in spite of the different models that were used. Several model features and assumptions about applied methods may be responsible for the differences in the 2 sets of sea-level projections: these are considered in this section. In Section 5 we will demonstrate the effects that some of these model features and assumptions have on our sea-level projections.

\subsection{Thermal expansion}

The climate sensitivity of the zonal mean climate model $\left(2.2^{\circ} \mathrm{C}\right)$ is slightly smaller than the prescribed central value $\left(2.5^{\circ} \mathrm{C}\right)$ in the $1 \mathrm{D}$ upwellingdiffusion model (Raper et al., 1996), but both models project almost the same increase in global mean atmospheric temperature. However, it can be seen from Table 1 that the amount of sea-level rise due to thermal expansion calculated with the $1 \mathrm{D}$ model is almost $2 \times$ as large as the amount calculated with the zonal mean climate model. Although a larger climate sensitivity value will cause a larger overall warming, the difference in climate sensitivity is too small to fully account for the difference in thermal expansion. But it can be concluded that the flux of heat into the ocean is larger in the 1D-model than in the zonal mean model. This larger heat flux is partly caused by a small difference in the upper ocean layer depth ( $90 \mathrm{~m}$ in the 1D-model and $75 \mathrm{~m}$ in the $2 \mathrm{D}$-model), but mainly by the assumption made in the $1 D$-model that changes in the ocean mixed-layer temperature are the same as the surface air temperature changes above the ocean. Therefore, the heat penetration into the top layers of the ocean is considerably faster in the $1 \mathrm{D}$-model than in the zonal mean climate model, because in the latter, the ocean mixed-layer temperatures are determined by radiative and turbulent heat fluxes at the surface and by heat exchange with the deep ocean. Thus, changes in the ocean mixed-layer temperature in the zonal mean climate model lag behind changes in surface air temperature. This aspect was also proposed by Raper and Cubasch (1996) to explain the overestimation of thermal expansion in the $1 \mathrm{D}$-model compared to a particular atmosphere-ocean general circulation model.

Several other model features can further contribute to the difference in thermal expansion. (i) Variations in thermal expansion coefficients due to meridional ocean temperature gradients, which are included in the zonal mean climate model, cannot be taken into account in the 1D-model, since in the $1 \mathrm{D}$-model, only hemispheric mean temperature profiles are considered. (ii) The seasonal cycle is not included in the $1 \mathrm{D}$ model, neither is sea ice (iii). The related temperature-

Table 1. Estimates of the individual contributions and total sea-level rise (cm) over the period 1990-2100, for the IS92a Scenario with aerosols constant at the 1990 level (I) and with the inclusion of aerosol changes (II)

\begin{tabular}{lccccc}
\hline \multicolumn{1}{c}{ Model/method } & $\begin{array}{c}\text { Thermal } \\
\text { expansion }\end{array}$ & $\begin{array}{c}\text { Glaciers, } \\
\text { ice caps }\end{array}$ & $\begin{array}{c}\text { Greenland } \\
\text { ice sheet }\end{array}$ & $\begin{array}{c}\text { Antarctic } \\
\text { ice sheet }\end{array}$ & $\begin{array}{c}\text { Total sea- } \\
\text {-level rise }\end{array}$ \\
\hline revised IPCC projections: I & 32 & 18 & 7 & -2 & 55 \\
projections in this paper: I & 17.5 & 14.6 & 10.4 & -8.5 & 34.0 \\
revised IPCC projections: II & 28 & 16 & 6 & -1 & 49 \\
projections in this paper: II & 15.2 & 12.3 & 7.2 & -7.5 & 27.2 \\
\hline
\end{tabular}


albedo feedback mechanism that is taken into account in the zonal mean model is assumed to be incorporated in the climate-sensitivity value of the 1D-model. Because the 1D-model has only vertical resolution (iv), the thermohaline circulation is represented merely by a globally averaged upwelling. Downwelling is assumed to happen outside the model boundaries, and therefore the change in the sea-surface temperature of the water that is assumed to downwell in the polar regions has to be specified: thermal expansion in the $1 \mathrm{D}$ model is affected by the choice of this specification (Wigley and Raper, 1993). Finally (v), some recent coupled GCM-results show a weakening of the North Atlantic thermohaline circulation as the globe warms (Manabe and Stouffer, 1994; Murphy and Mitchell, 1995). This weakening is related to a stabilisation of the water column that is caused mainly by an increase in the net surface freshwater flux arising from increased precipitation at high latitudes. In the 1D-model, an attempt is made to take this effect into account by forcing the global upwelling rate to reduce as the temperature of the global mixed-layer increases. The prescribed thermohaline circulation in the zonal mean climate model is kept constant. For any given ocean surface warming, decreasing the upwelling rate tends to increase the thermal expansion, because the ocean tends to move towards a warmer isothermal state.

\subsection{Glaciers}

In the revised IPCC-projections, the contributions of glaciers and ice caps were estimated with a global glacier melt model that was forced by the projected increase in global and annual mean surface air temperature referenced to the year 1880 (Wigley and Raper, 1995). In our projections, the changes in the volume of glaciers and ice caps are estimated by the use of a range of precipitationdependent sensitivity values and by the use of latitudinally- and seasonally-varying changes in surface air temperature referenced to the year 1990. Accounting for seasonal and latitudinal temperature forcing affects the calculation of the sealevel contribution of glaciers and ice caps. Since the projected atmospheric warming increases polewards (Fig. 1), the temperature forcing is larger for high-latitude glaciated regions than for lowlatitude glaciated regions. Summer warming is projected to be smaller than winter warming. Since glacier melting occurs, particularly in summer, the projected ablation rates are smaller when the lower temperature changes occurring during summer are taken into account than when annual mean temperature changes are used. In spite of these differences in approach, the 2 projections of sea-level rise, due to changes in the volume of glaciers and small ice caps, do not differ much.

\subsection{Greenland ice sheet}

For the sea-level contribution of the Greenland ice-sheet in the revised IPCC-projections, the assumption is made that the dynamic response of the ice-sheet can be ignored on the time-scale of decades to a century. Changes in the surface mass balance are assumed to result from enhanced ablation, but are represented by a constant sensitivity for which a central value of $0.30 \mathrm{~mm} / \mathrm{yr}$ sealevel equivalent per $1^{\circ} \mathrm{C}$ was taken (but a large uncertainty range was considered in the extreme projections). Although this value is based on present-day conditions, calculations are performed with temperature changes that are referenced to the year 1880 . In order to account for a polar amplification of the projected temperature increase seen in most GCM results (and also in the results of the zonal mean climate model), the projected change in global and annual mean surface air temperature was multiplied by a factor 1.5 after 1990 . In our projections, we used a dynamic icesheet model of Greenland, coupled to a mass balance model which was forced by the projected latitudinally and seasonally varying changes in surface air temperature. Since the model is tuned to present-day conditions, temperature changes are referenced to the year 1990 and are therefore smaller than when referenced to any arbitrary pre-1990 date. Ablation is calculated with an energy-balance model, which has a similar model sensitivity for a $1^{\circ} \mathrm{C}$ increase in surface air temperature for the present-day climate as the constant central sensitivity value of $0.30 \mathrm{~mm} / \mathrm{yr}$ per $1^{\circ} \mathrm{C}$. However, due to the non-linear temperaturealbedo feedback, the model sensitivity increases for increasing temperature changes (Van de Wal, 1996). Nevertheless, the projected sea-level contributions of the Greenland ice-sheet do not differ much in the 2 sets of projections. 


\subsection{Antarctic ice sheet}

In both sets of sea-level projections, the Antarctic ice sheet contributes to a sea-level drop due to an increased accumulation rate, but the projected magnitudes of sea-level drop differ enormously. The sea-level contribution of the Antarctic ice sheet in the revised IPCC-projections is estimated by the use of a constant sensitivity value. This value, for which a central value of $-0.2 \mathrm{~mm} / \mathrm{yr}$ sea-level equivalent per $1^{\circ} \mathrm{C}$ was taken, includes a term for the possible instability of the west Antarctic ice-sheet, although it was concluded in the IPCC96-report that given our present knowledge, estimating the likelihood of a collapse during the next century is not yet possible (Warrick et al., 1996). It was also concluded that there is insufficient evidence, either from models or observations, to say whether the present-day average mass balance of the Antarctic ice-sheet is positive or negative. Nevertheless, in the revised IPCC-projections, an imbalance of $+0.1 \mathrm{~mm} / \mathrm{yr}$ (central value, equivalent sea-level rise) in 1880 is assumed for the Antarctic ice-sheet and is extrapolated over the entire simulation period. However, for the extreme projections of global mean sealevel rise, these values were varied within a wide range of uncertainty (Raper et al., 1996). The projected annual and global mean temperature changes referenced to the year 1880 were used to calculate the Antarctic sea-level contribution (unlike the Greenland sea-level projections, no significant polar amplification of the temperature change was assumed for Antarctica).

Our projections are based on a dynamic icesheet model for Antarctica coupled to a surface mass balance model which is driven by latitudinally and seasonally varying changes in surface air temperature, referenced to the year 1990. Because the projected atmospheric warming increases polewards (Fig. 1), the forcing of the ice-sheet model would be reduced if the annual and global mean temperature increase (referenced to the year 1990) had been used. On the time scales considered here, model changes in the mass balance are dominated by the projected increase in accumulation. Since the accumulation rate in the model is perturbed in proportion to the saturation water vapour pressure, the model sensitivity to a $1{ }^{\circ} \mathrm{C}$ increase in surface air temperature is $-0.36 \mathrm{~mm} / \mathrm{yr}$ sealevel equivalent with respect to present conditions
(Huybrechts and Oerlemans, 1990), but it increases slightly with increasing surface temperatures. In our projections we do not include any long-term trend or possible instability of the west Antarctic ice-sheet, which would produce a positive contribution to sea-level rise. All these differences in models, in model forcings and in assumptions about the ice-sheet conditions, contribute to the large differences in the estimated sea-level contributions of the Antarctic ice-sheet in the 2 sets of sea-level projections.

\section{Sensitivity experiments}

In this section, we present some additional model runs in which we tested alternative assumptions about models and methods, in order to investigate their effects on the sea-level projections. The alternative methods were chosen on the basis of the models and methods that were used in the revised IPCC-projections. The sensitivity experiments are carried out for the updated IS92a radiative-forcing scenario with constant aerosols after 1990, since this scenario is the middle estimate of all scenarios and it excludes the uncertainties caused by possible aerosol changes after 1990. However, similar results would have been found if another radiative-forcing scenario had been selected. However, firstly, we will demonstrate the uncertainties in thermal expansion which are caused by the ocean heat mixing, since thermal expansion is the largest contributor to sea-level rise.

\subsection{Ocean heat mixing}

Ocean heat mixing plays an important rôle in thermal expansion. Since neither the 1D-model nor the zonal mean climate model resolves eddies (neither do coupled GCMs), the ocean heat mixing by eddies in these models is parameterized in terms of diffusion, but the values of the diffusion coefficients are very uncertain. The sea-level projections presented in Fig. 3, 4 were obtained by using a constant vertical diffusion coefficient of $1 \mathrm{~cm}^{2} \mathrm{~s}^{-1}$. This value was also used in the 1D-model to produce the central estimates. For the updated IS92a, radiative forcing-scenario (constant aerosols), we performed 4 additional model runs in which various parameterizations of the 
ocean heat mixing were used. In the first 2 model runs, we doubled and halved the vertical diffusivity $\left(2.0 \mathrm{~cm}^{2} \mathrm{~s}^{-1}\right.$ and $0.5 \mathrm{~cm}^{2} \mathrm{~s}^{-1}$, respectively) to investigate the importance of the magnitude of the diffusion coefficient. In the 3 rd model run, the vertical diffusivity was made dependent on the stability of the water column, as suggested by Gargett (1984), and in the 4th model run, the concept of isopycnal diffusion was implemented, using the technique introduced by Redi (1982). For all parameterizations, the climate model was integrated to a pre-industrial model equilibrium state, and the climate scenario runs were then performed.

Fig. 5 shows the projected sea-level rise due to thermal expansion for the different parameterizations of the ocean heat mixing. Even over the first few decades, the projected sea-level rise due to thermal expansion varies considerably. The smallest rates of thermal expansion are found when the diffusivity is stability-dependent: in this case, diffusion coefficients vary with depth and with latitude. The largest expansion rates are found when a uniform vertical diffusion coefficient of $2.0 \mathrm{~cm}^{2} \mathrm{~cm}^{-1}$ is chosen. Although the choice of the model heat-mixing parameters mainly affects the ocean temperature field, it also has a slight effect on the projected atmospheric warming, because the atmosphere and the oceans interact. In spite of the slightly different temperature forcings of the land ice models, the projected land ice contributions are nearly similar for all model

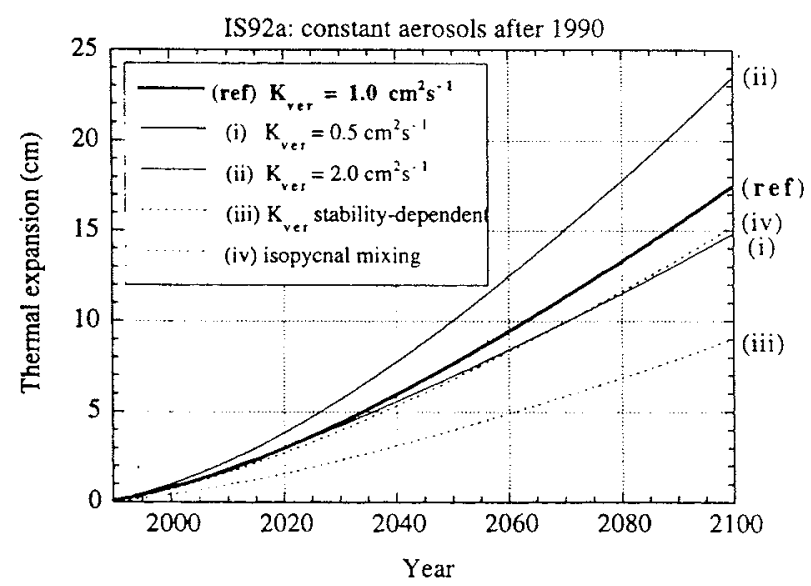

Fig. 5. Sea-level contribution of thermal expansion $(\mathrm{cm})$ from 1990 to 2100 for the updated IS92a Scenario with aerosols constant at the 1990 level: results are shown for the reference case and for 4 alternative parameterizations of the ocean heat mixing. runs. The total projected sea-level rise by the year 2100 for the IS92a scenario (constant aerosols) varies from $25 \mathrm{~cm}$ in the case of stabilitydependent diffusivity (case (iv) in Fig. 5) to $40 \mathrm{~cm}$ in the case of doubled vertical diffusion coefficient (case (iii) in Fig. 5).

\subsection{The ocean circulation}

Some coupled GCM-results show a weakening of the thermohaline circulation as the globe warms. In a transient experiment carried out with the UKMO-model (United Kingdom Meteorological Office), this weakening is restricted mainly to the Northern Atlantic Ocean and does not begin until after year 30 of the experiment (Murphy and Mitchell, 1995). In a 500-year integration of the GFDL-model (Geophysical Fluid Dynamics Laboratory), a weakening of the thermohaline overturning is found in the Northern Atlantic and in the vicinity of Antarctica (Manabe and Stouffer, 1994). However, the thermohaline circulation in the Northern Atlantic in the GFDLmodel in the $2 \times \mathrm{CO}_{2}$ run recovers after several decades, almost regaining its original intensity. The weakening of the thermohaline circulation in both GCMs is related to a stabilisation of the water column that is caused mainly by an increase in the net surface freshwater flux arising from increased precipitation at high latitudes. The recovery of the North Atlantic circulation in the GFDL-model is related to a continuous warming of surface ocean layers in low and middle latitudes, which causes an increase in density contrast between sinking and rising regions in the ocean.

The weakening of the thermohaline circulation in GCMs obviously results from a complicated interaction between atmosphere and oceans brought about by anomalies in both heat and freshwater fluxes. In the zonal mean climate model, the hydrological cycle is not considered and it is not completely clear how variations in the ocean circulation seen in GCM-results could be included in the zonally-averaged three-basin ocean system. It was therefore decided to keep the circulation unchanged. However, in the 1D upwellingdiffusion model that was used for the IPCCprojections (and that does not consider the hydrological cycle either), it was assumed that a weakening of the thermohaline circulation can be taken into account by forcing the hemispheric 
upwelling rate to reduce when the temperature of the hemispheric ocean mixed-layer increases (Kattenberg et al., 1996; Raper et al., 1996). A linear relationship between the upwelling rate $W(t)$ and the ocean mixed-layer temperature change $\Delta T$ has been chosen so that $W(t)=W_{0}(1-$ $\left.\Delta T / \Delta T^{*}\right)$. The initial upwelling rate $W_{0}=4 \mathrm{~m} \mathrm{yr}^{-1}$ and the threshold temperature change $\Delta T^{*}=$ $7.0^{\circ} \mathrm{C}$.

For any given ocean-surface warming, a decrease in the upwelling rate tends to increase thermal expansion, because the ocean tends to move towards an isothermal state which causes a greater warming at depth. The results of the larger thermal expansion in the IPCC-projections will thus be caused at least partly by the difference between the transient responses of the upwelling rate in the $1 \mathrm{D}$ upwelling-diffusion model and in the zonal mean climate model. In order to investigate which part of the difference in sea-level rise can be accounted for by the upwelling rate, we performed a sensitivity run (experiment 1 ) in which we imposed the same reduction of the hemispheric upwelling rate in the zonal mean model as in the 1D-model: we calculated a hemispheric average change in mixed-layer temperature over all 3 ocean basins $(\Delta T)$ and forced the upwelling rate $(W)$ in each hemisphere (and in all ocean basins) to reduce according to the mixed-layer temperature change in that hemisphere, so that $W(t)=$ $W_{0}\left(1-\Delta T / \Delta T^{*}\right)$. As in the 1D-model, we used an initial upwelling rate of $W_{0}=4 \mathrm{~m} \mathrm{yr}^{-1}$ and a threshold temperature change of $\Delta T^{*}=7.0^{\circ} \mathrm{C}$.

Since a reduction in the upwelling rate causes an increase in the heat uptake by the oceans, the atmospheric warming at the end of this integration is smaller than when the upwelling rate was kept constant, especially at high-latitudes. We therefore performed additional runs with the ice models too, in which the models were driven by the reduced atmospheric warming. Table 2 shows the individual sea-level contributions for this sensitivity run (experiment 1) for year 2100 (relative to 1990 ), as well as the reference values for comparison. By the year 2100 , sea-level rise due to thermal expansion in the zonal mean climate model is about $5 \mathrm{~cm}$ higher, when the reduction in hemispheric upwelling rate is included. The sea-level contributions of glaciers and small ice caps, the Greenland and the Antarctic ice-sheet, are all reduced because of the lower atmospheric warm- ing, but their combined contribution is almost unchanged.

Thus, so even when a similar forced reduction in hemispheric upwelling rate is included in the zonal mean climate model, the estimated contribution of thermal expansion $(22.8 \mathrm{~cm})$ and the estimated total sea-level rise $(38.9 \mathrm{~cm})$ are still considerably smaller than in the corresponding IPCC-projection $(32 \mathrm{~cm}$ and $55 \mathrm{~cm}$, respectively). The forced reduction in the upwelling rate in the 1D upwelling-diffusion model can therefore only explain a small part of the differences in both sets of sea-level projections.

\subsection{The temperature forcing of the ice models}

In the 2 sets of sea-level projections, very different models are used to estimate sea-level changes due to changes in land ice volume. The most important difference lies in the fact that we used dynamic ice-flow models coupled to mass-balance models in our projections for the Greenland and Antarctic ice sheets, whereas constant sensitivity values were used in the revised IPCC-projections: this point will be further considered in Subsection 5.4. However, the temperature forcings of the 2 sets of ice models are also defined in very different ways. In the revised IPCC-projections, the ice models were driven by annual and global mean-surface air-temperature changes referenced to the year 1880 and multiplied by a factor 1.5 (after 1990) for the Greenland calculations. In our projections, seasonally and latitudinally varying changes in surface air temperature referenced to the year 1990 are used to drive the ice models. In order to demonstrate the effect that these differences in temperature forcing have on the projected sea-level rise, we performed some experiments in which our ice models were driven by different temperature forcings. Since these temperature forcings are calculated from the same model output as produced by the zonal mean climate model, the sea-level contribution of thermal expansion is the same in all experiments.

We first tested the effect of the seasonality of the temperature forcing on the projected sea-level rise by forcing the ice models with the annual mean, but latitudinally varying surface-air temperature changes referenced to the year 1990. The sea-level results for this experiment (2) are shown in Table 2. The sea-level contributions of glaciers 
Table 2. Estimates of the individual contributions and total sea-level rise (cm) over the period 1990-2100, for the IS92a Scenario with aerosols constant at the 1990 level

\begin{tabular}{lccccc} 
Case & $\begin{array}{c}\text { Thermal } \\
\text { expansion }\end{array}$ & $\begin{array}{c}\text { Glaciers, } \\
\text { ice caps }\end{array}$ & $\begin{array}{c}\text { Greenland } \\
\text { ice sheet }\end{array}$ & $\begin{array}{c}\text { Antarctic } \\
\text { ice sheet }\end{array}$ & $\begin{array}{c}\text { Total sea- } \\
\text {-level rise }\end{array}$ \\
\hline ref. & 17.5 & 14.6 & 10.4 & -8.5 & 34.0 \\
$(1)$ & 22.8 & 13.5 & 8.9 & -6.3 & 38.9 \\
$(2)$ & 17.5 & 16.2 & 11.2 & -8.3 & 36.6 \\
$(3)$ & 17.5 & 13.4 & 6.4 & -4.6 & 32.7 \\
$(4)$ & 17.5 & 11.4 & 13.0 & -11.2 & 30.7 \\
$(5)$ & 17.5 & 14.6 & 6.8 & -9.1 & 29.8 \\
\hline
\end{tabular}

(1) Including forced reduction in the ocean upwelling rate.

(2) Ice models forced with annual mean, but latitudinally varying temperature changes.

(3) Ice models forced with annual and global mean temperature changes.

(4) Temperature changes referenced to 1880.

(5) Constant sensitivities for the Greenland and Antarctic ice sheets.

and of the Greenland ice-sheet are about $10 \%$ larger when the annual mean temperature forcing is used than when a seasonally varying temperature forcing is used. The Antarctic sea-level contribution is almost unchanged. Because glacial melting occurs, especially in summer, and the projected summer warming is smaller than the projected winter warming, the sea-level contribution of glaciers and Greenland is smaller when the seasonality is taken into account. Since the change in the Antarctic mass balance is not determined primarily by glacial melting, but by changes in the accumulation rate, which depends mainly on the annual mean temperature, the Antarctic sea-level contribution is not affected by the seasonality of the temperature forcing.

We then tested the effect of the latitudinal variation of the temperature forcing by driving the ice models with the global and annual mean surface-air temperature change referenced to the year 1990 (experiment 3). The corresponding sealevel results are included in Table 2. Because the projected atmospheric warming increases polewards in both hemispheres, the temperature forcings of the Antarctic and Greenland ice sheets models are strongly reduced when the global mean atmospheric warming is selected as model-input. Consequently, the projected sea-level contributions of Greenland and Antarctica are strongly reduced. Because glaciers and small ice caps are scattered more widely over the earth and because a long-term trend, independent of the atmospheric warming is included in our projections, the reduction in the sea-level contribution of glaciers and small ice caps is relatively smaller. The sea-level contributions of Greenland and Antarctica calculated in this experiment seem to fit reasonably with the revised IPCC-projection. However, this is somewhat misleading, since our ice models were driven with temperature changes referenced to the year 1990, whereas the temperature changes used in the IPCC-projections were referenced to the year 1880 .

Finally, we tested the effect of the reference year in the calculations (experiment 4). In all our projections, the ice models were driven by temperature changes referenced to the year 1990. Since the model sensitivities depend on the initial model states, a pre-present start of the model calculations would require initial model states that correspond to the conditions of glaciers and ice sheets in the past. Since observational data are insufficient to define such initial model states, we decided to start our model calculations in 1990. In the revised IPCC-projections, model calculations started in 1880 , although the sensitivity values that were used were determined for present-day conditions. Temperature changes referenced to the year 1880 are larger than when referenced to the year 1990 . Thus, the temperature forcing of the ice models is larger when 1880 is selected as the initial year of the simulations and projected sea-level changes due to changes in land-ice volume after 1990 are therefore larger. In order to consider this effect, we revised the ice-model calculations incorporating seasonally and latitudinally varying temperature changes referenced to the year 1880 instead of 1990. The individual contributions to sea-level 
rise over the period 1990-2100 are included in Table 2 (experiment 4). Due to the increased model forcing, the projected sea-level contribution of the Greenland ice-sheet is $25 \%$ larger and that of the Antarctic ice-sheet is about $30 \%$ larger. However, because these calculations start in 1880 , the longterm correction for present-day disequilibrium of most glaciers is excluded in this particular experiment. The projected sea-level contribution of glaciers and small ice caps in experiment 4 is therefore smaller than in the previous experiments in which the long-term trend was included, in spite of the larger temperature forcing. Because the glaciers and small ice caps contribute less and because the increases in the contribution of the Greenland and Antarctic ice sheets partly balance each other, the total projected sea-level rise over the period $1990-2100$ is smaller when 1880 is chosen as the initial year of the simulations.

\subsection{The non-linear response of the ice sheet mass balance models}

A major difference between the revised IPCCprojections and our sea-level projections is that we used dynamic ice flow models coupled to surface mass balance models to estimate the sealevel contributions of Greenland and Antarctica. Although the dynamic response of the models is limited on time scales considered here, the use of surface mass balance models instead of constant sensitivity values clearly affects the sea-level projections. Since the sensitivity of the surface mass balance models depends on the magnitude of the temperature forcing, the coupled ice-sheet models respond in a non-linear way to a changing climatic input. To study the effect of these non-linear model responses on the century time scale, we recalculated the sea-level contributions of the Greenland and Antarctic ice sheets by means of constant sensitivity values (experiment 5). For the Antarctic ice-sheet, the sensitivity value was $-0.36 \mathrm{~mm} / \mathrm{yr}$ sea-level equivalent per $^{\circ} \mathrm{C}$ temperature increase with respect to present conditions (Huybrechts and Oerlemans, 1990). To obtain a sensitivity value for the Greenland ice-sheet, we forced the energy-balance model (Van de Wal and Oerlemans, 1994) with $\mathrm{a}+1^{\circ} \mathrm{C}$ increase in the surface-air temperature and integrated the model to equilibrium using a fixed prescribed ice-sheet geometry. From the change in mass balance, we calculated a sensitivity value $(\mathrm{mm} / \mathrm{yr}$ sea-level equivalent) for each land strip of 5 meridional degrees which corresponds to the model resolution of the zonal mean climate model. We then assumed the sensitivity values for the Greenland and Antarctic ice sheets to be valid for larger temperature forcings too and recalculated their sea-level contributions using the seasonally- and latitudinally-varying temperature forcing referenced to the year 1990. Because a single sensitivity value was defined for the Antarctic ice-sheet, we averaged the temperature changes of the 4 southernmost model strips in the zonal mean climate model in order to calculate the Antarctic sea-level contribution.

Table 2 includes the sea-level contributions of the Greenland and Antarctic ice sheets which are determined by means of these constant sensitivity values (experiment 5). With regard to the Greenland ice-sheet, ignoring the non-linear mass balance model response results in a $35 \%$ underestimation of the sea-level contribution. Because the ablation of the Greenland ice-sheet is calculated with an energy-balance model, changes in the surface albedo, due to melt, affect the amount of solar radiation that is absorbed. This albedotemperature feedback mechanism causes the model to be increasingly sensitive to increasing temperature changes. This mechanism is neglected if constant sensitivity values are assumed. Changes in the mass balance of the Antarctic ice-sheet are controlled mainly by changes in the accumulation rate, which in turn is related to the saturation water vapour pressure. Consequently, the Antarctic sea-level contribution is only slightly affected by the assumption of a constant sensitivity value.

\section{Conclusion}

We have presented sea-level projections that we calculated using a zonal mean climate model to estimate thermal expansion, precipitationdependent sensitivity values to estimate the contribution of glaciers and small ice caps and dynamic ice-flow models coupled to surface-mass balance models to estimate the contributions of the Greenland and Antarctic ice sheets. For all updated IS92 radiative-forcing scenarios, these sea-level projections are found to be considerably 
smaller than the revised IPCC-projections which are based on a 1D upwelling-diffusion model, on a global glacier-melt model and on static sensitivity values for the ice sheets (Warrick et al., 1996).

The largest differences in individual sea-level contributions relate to thermal expansion of sea water. Calculations performed with the zonal mean climate model demonstrate that the rate of thermal expansion is very dependent on the model parameters that determine ocean heat mixing. Uncertainties in the total sea-level projections caused by uncertainties in these mixing parameters are just as large as the uncertainties introduced by the various radiative-forcing scenarios! However, if identical ocean-heat mixing parameters are choosen in both models, thermal expansion in our zonal mean climate model is about half the amount that is calculated with the $1 \mathrm{D}$ upwelling-diffusion model. In the IPCC96-report (Warrick et al., 1996), it is suggested that this difference is caused mainly by a forced reduction in the upwelling rate in the $1 \mathrm{D}$-model, whereas the ocean circulation was kept constant in the zonal mean climate model. We showed that only a part of the difference in thermal expansion can be explained by this inter-model difference in upwelling rate. Other possible explanations for the inter-model differences in thermal expansion include differences in model features such as a small difference in climate sensitivity, the absence of sea ice, meridional resolution and seasonal cycle in the $1 \mathrm{D}$-model and the way in which heat penetrates in the ocean. In contrast to our zonal mean climate model, the change in ocean mixedlayer temperature in the $1 \mathrm{D}$-model is assumed to equal the surface air temperature change above the ocean. As a consequence, there is a greater heat penetration into the uppermost layer in the $1 \mathrm{D}$-model. This probably leads to an overestimation of the ocean thermal expansion in the 1D-model.

The estimated sea-level contributions of glaciers and small ice caps in the 2 sets of projections do not differ much, despite the very different models used. For the IPCC-projections, a global melt model was used that was forced with global mean temperature changes referenced to 1880 . We used precipitation-dependent sensitivity values and seasonally and latitudinally varying temperature changes referenced to 1990, and we included a long-term trend correction to account for the present-day disequilibrium of most glaciers. These differences in models and in model forcings have counterbalancing effects, with the result that the IPCC estimates and our estimates of the sea-level contribution of glaciers and small ice caps are similar.

To estimate the sea-level contribution of Greenland, we used a dynamic ice flow model coupled to a mass-balance model that has a nonlinear response to a changing climatic input. We demonstrated that the sea-level contribution of Greenland is strongly reduced when constant sensitivity values are used (as in the revised IPCCprojections). However, we also demonstrated that the sea-level contribution of Greenland increases when the seasonality of the temperature forcing is neglected or when a pre-present date is selected as the initial year of integration. It can therefore be concluded that the integration of the coupled mass-balance-ice-flow model for Greenland gives a different estimate of the sea-level contribution on the century time-scale than calculations based on constant sensitivity values. However, our projections and the IPCC-projections do not differ very greatly, because the differences in models and in model forcings have counterbalancing effects.

The inter-model differences in the Antarctic sealevel contribution were found to be substantial. We demonstrated that on the century time-scale, the response of the Antarctic ice-sheet model is only slightly affected by the ice-flow dynamics. However, the Antarctic sea-level contribution is affected considerably when the ice-sheet model is forced by a global and annual mean temperature change or by temperature changes that are referenced to 1880 (as in the IPCC-projections). Two other aspects seem to be responsible for the intermodel differences in the Antarctic sea-level contribution: an extrapolated baseline trend is included in the IPCC-projections because it was assumed that the mass balance of the Antarctic ice-sheet was negative in 1880 and a strikingly small sensitivity value is used in the IPCC-projections, because the value includes a term for the possible instability of the west-Antarctic ice sheet.

In the 2 sets of sea-level projections, different assumptions were made about the temperature forcing of the glacier and ice-sheet models. We performed sensitivity experiments which show that the applied differences in temperature forcing have large effects on the individual sea-level contribu- 
tions. However, due to counterbalancing effects, the projections of total sea-level rise are only slightly affected by the differences in model forcings. The small range of sea-level projections in our sensitivity experiments indicate that neither the differences in temperature forcing of the glacier and ice-sheet models nor the forced reduction in upwelling rate in the $1 \mathrm{D}$ upwelling-diffusion model, can fully explain the considerably varying sea-level results in the 2 sets of projections. It is concluded that the major part of the inter-model differences in sea-level results can be accounted for by essentially different model features. It might therefore be beneficial to reconsider the approach followed in the IPCC96-report (Warrick et al.,
1996) that only the simplest models available should be used to produce sea-level projections.

\section{Acknowledgements}

Financial support was obtained from Rijkswaterstaat (RIKZ), The Netherlands Geosciences Foundation (GOA) with aid from The Netherlands Organization for Scientific Research (NWO), the Belgian National Fund for Scientific Research (NFWO) and the Belgian Impulse Programme on Global Change (Federal Office for Scientific, Technical and Cultural Affairs. Services of the Prime Minister).

\section{REFERENCES}

Bintanja, R. 1997. Sensitivity experiments performed with an energy balance atmosphere model coupled to an advection-diffusion ocean model. Theor. Appl. Climatol. 56, 1-24.

De Wolde, J. R., Bintanja, R. and Oerlemans, J. 1995. On thermal expansion over the last hundred years. J. Climate 11, 2881-2891.

Gargett, A. E. 1984. Vertical eddy diffusivity in the ocean interior. J. Mar. Res. 42, 359-393.

Huybrechts, P. 1990. A 3-D model for the Antarctic ice sheet: a sensitivity study on the glacial-interglacial contrast. Climate Dynamics 5, 79-92.

Huybrechts, P. and Oerlemans, J. 1990. Response of the Antarctic ice sheet to future greenhouse warming. Climate Dynamics 5, 93-102.

Huybrechts, P., Letreguilly, A. and Reeh, N. 1991. The Greenland ice sheet and greenhouse warming. Palaeogeog. Palaeoecol. Palaeoclim (Global and Planetary Change section) 89. 399-412.

Kattenberg, A., Giorgi, F., Grassl, H., Meehl, G. A., Mitchell, J. F. B., Stouffer, R. J., Tokioka, T., Weaver, A. J. and Wigley, T. M. L. 1996. Climate Models Projections of Future Climate. In: Climate Change 1995: The science of climate change, J. T. Houghton, L. G. Meiro Filho. B. A. Callander, N. Harris, A. Kattenberg and $\mathrm{K}$. Maskell (eds.). Cambridge Univ. Press. 285-357.

Manabe, S. and Stouffer, R. J. 1994. Multiple-century response of a coupled ocean-atmosphere model to an increase of atmospheric carbon dioxide. J. Climate 7, 5-23.

Meier. M. F. 1984. Contribution of small glaciers to global sea level. Science 266, 1418-1421.

Mitchell, J. F. B., Manabe, S., Meleshko, V. and Tokioka, T. 1990. Equilibrium climate change and its implication for the future. Climate change: the IPCC Scientific Assessment. J. T. Houghton, G. J. Jenkins and J. J. Ephraums (eds.). Cambridge Univ. Press. 131-172.
Murphy, J. M. and Mitchell, J. F. B. 1995. Transient response of the Hadley Centre coupled oceanatmosphere model to increasing Carbon Dioxide. Part II: spatial and temporal structure of response. J. Climate 8, 57-80.

Oerlemans, J. and Fortuin, J. P. F. 1992. Sensitivity of glaciers and small ice caps to greenhouse warming. Science 258, 155-117.

Ohmura A. and Reeh N. 1991. New precipitation and accumulation maps for Greenland $J$. Glaciolog! 37(125), 140-148.

Ohmura, A., Wild, M. and Bengtsson L. 1996. A possible change in mass balance of Greenland and Antarctic ice sheets in the coming century. J. Climate 9. 2124-2135.

Raper, S. C. B. and Cubasch, U. 1996. Emulation of the results from a coupled general circulation model using a simple climate model. Geoph. Res. Lett. 10. $1107-1110$.

Raper, S. C. B., Wigley, T. M. L. and Warrick, R. A. 1996. Global sea-level rise: past and future. in: Sealevel rise and coastal subsidence: causes, consequences and strategies, J. D. Milliman and B. U. Haq (eds.). Kluwer Academic Publishers, Dordrecht, 384pp.

Redi, M. H. 1982: Oceanic isopycnal mixing by coordinate rotation. J. Phys. Oceanogr. 12, 1154-1158.

Schwitter, M. P. and Raymond, C. F. 1993. Changes in the longitudinal profiles of glaciers during advance and retreat. J. Glaciol. 39 (133), 582-590.

Van de Wal, R. S. W. and Oerlemans. J. 1994. An energy balance model for the Greenland ice sheet. Global and Planetary' Change 9, 115-131.

Van de Wal, R. S. W. 1996. Mass-balance modelling of the Greenland ice sheet: a comparison of an energy balance and a degree-day model. Annuls of Glaciolog! 23, 36-45.

Van de Wal, R. S. W. and Oerlemans, J. 1997. Modelling 
the short-term response of the Greenland ice sheet to global warming. Climate Dynamics, in press.

Warrick, R. A. and Oerlemans, J. 1990. Sea-level rise. In: Climatic change: the IPCC scientific assessment, J. T Houghton, G. J. Jenkins and J. J. Ephraums (eds.). Cambridge Univ. Press, 257-282.

Warrick, R. A., Le Provost, C., Meier, M. F., Oerlemans, J. and Woodworth, P. L. 1996. Changes in sea-level. In: Climate Change 1995: The science of climate change, J. T. Houghton, L. G. Meiro Filho, B. A. Callander, N. Harris, A. Kattenberg and K. Maskell (eds.). Cambridge Univ. Press, 359-405.
Wigley, T. M. L. and Raper, S. C. B. 1992. Implications for climate and sea level of revised IPCC emissions scenarios. Nature 357, 293-300.

Wigley, T. M. L. and Raper, S. C. B. 1993. Future changes in global mean temperature and sea level. In: Climate and sea level change: observations, projections and implications, R. A. Warrick, E. M. Barrow and T. M. L. Wigley (eds.). Cambridge Univ. Press, 111-133.

Wigley, T. M. L. and Raper, S. C. B. 1995. An heuristic model for sea level rise due to the melting of small glaciers. Geophys. Res. Lett. 22, 2749-2752. 